\title{
Risk Management in Laboratory Quality Control of Pesticides
}

\author{
Rita de Cássia Boccuzzi Prisco, Vera Lúcia Tedeschi Savoy \\ Biological Institute, São Paulo, Brazil \\ Email: rprisco@biologico.sp.gov.br
}

Received 7 December 2013; revised 7 January 2014; accepted 14 January 2014

Copyright (C) 2014 by authors and Scientific Research Publishing Inc.

This work is licensed under the Creative Commons Attribution International License (CC BY). http://creativecommons.org/licenses/by/4.0/

(c) (i) Open Access

\begin{abstract}
Risk assessment is the scientific process of estimating how much damage, a specific hazard can cause to human health. The preparation of an environmental risk map creates an overview, showing the way how risks are felt and seen by the workers. Through risk quantification tools, the management is used to make decisions to improve the environment achieving a better environment. The objective of this study was to identify and prepare a map of environmental risk of a laboratory unit for analytical chemistry which performs tests for pesticides quality control, to manage the risks of occupational accidents. The methodology for risk identification method used was the checklist used in 14 areas encompassing the laboratory unit. The results of the evaluation of occupational risk related to facilities and equipments of the laboratory unit were grouped into the categories of physical, chemical, ergonomic and accidental risk and then developed the risk map based on the contribution of the employees of the unit.
\end{abstract}

Keywords

Risk Management; Occupational Health; Risk Map; Analytical Chemistry

\section{Introduction}

Despite the current concern about environmental risk, this issue is detected from the earliest civilizations. According to Bernstein [1], the word risk is derived from the old Italian risicare, which means daring.

Risk means the probability of occurrence of a harmful or undesirable event, such as source of natural phenomena, coming from industrial activities developed by man, disease, death, economic loss or environmental damage.

Risk assessment is the scientific process of estimating how much damage can cause a specific hazard to human health [2]. 
Risk analysis is the process involving hazard identification, estimation of each type of risk and risk assessment itself.

Risk map is a graphical representation that shows the risks that are felt and seen by the workers themselves, according to their sensitivity, which can lead to health workers.

On the work environment, we distinguish among different types of risk:

- Chemical risk (harmful substances)

- Fire and explosions

- Physical risk (radiation, magnetism, temperature, pressure)

- Hazard (cut, chop, beat, shake, crush...)

- Unexpected actions (glass breakage, leakage, power failure, failure in safety equipment)

- Lack of PPE (Personal Protect Equipment)

- Administrative failure of responsibilities, emergency procedures, guidance and education and training

- Electrical hazards

- Ergonomic risks

- Working conditions such as environment, length of journey and security equipment

- Psychological risks such as stress, conflict and distraction.

Therefore, this study aimed to map for environmental risk within a Unit of Chemistry Laboratory that performs tests for quality control of pesticides in order to identify, prevent, control and /or minimize the risk of occupational accidents.

\section{Legal and Regulatory Requirements on Pesticide Handling in Laboratory}

The handling of pesticides in the laboratory is the object of the norm ABNT NBR 13075 [3] of the Brazilian Association of Technical Standards (ABNT), which provides guidance on the safety requirements to be followed, divided between equipment and glassware, garbage disposal sites, personal protective equipment (PPE), handling of samples, packaging samples, actions in case of leak or spill, smoking and eating when handling and guidance on the analyst. Another norm is to respect the ABNT NBR 13073 [4], which treats the cleaning process for glassware used in testing of pesticides like.

The information on chemicals related to chemical, toxicological, ecotoxicological, first aid measures, control for spill or leak, transportation, handling, storage and disposal are compiled in safety data sheets of chemicals (MSDS), which should be available to technicians who handle them.

Occupational safety measures relevant to the laboratory include the creation of an internal committee of accident prevention (CIPA as a regulatory norm NR-5) and the control of environmental risks according to NR-9 (environmental hazards) approved by Ministry of Labour [5].

Another standard, although not compulsory its application in the case study on the subject of this article, is the norm of P4.261 Environmental Company of the State of São Paulo (CETESB), which features the "Guidance Manual for Development Studies Risk Analysis [6].

\subsection{Risk Management}

\subsubsection{Identification of Risk}

Regarding the identification of risk, which aims at realizing an estimate qualitative and/or quantitative risk, in order to promote the combination of frequencies with the magnitude of unwanted events, there are the following methods recommended in the literature:

- Preliminary Risk Analysis

- Hazop (Hazard Analysis and Operability: Hazard and Operability Analysis)

- Failure Modes

- Check list

\subsubsection{Risk Assessment}

Risk assessment is the process that uses the results of its identification, assigning each risk the Magnitude of Consequences (MC) and the Probability of Occurrence (PO) of an event, whereby.

MC evaluates the effect that an event can cause and PO examines the frequency a risk occurs PMBOK [7]. 


\subsubsection{Preventive and Corrective Measures}

Extracting results from matrix MC versus PO, we have areas of intervention, applying the preventive and corrective measures in risk management, prioritizing hierarchy that generally operate on the probability (which reduce the chance of occurrence of event) in relation to that act on the magnitude (that minimize the consequences):

- Elimination/replacing equipment and products

- Minimization using Personal Protective Equipment and Collective

- Isolation

- Training

- Awareness

\subsection{Development of Risk Map}

Risk map is a graphic representation drawn from the floorplan of a unit signaling and reporting, through visualization possible risks with information necessary to enable security for workers. Consequently stimulates and motivates employee participation in the attitudes of risk prevention.

\section{Methodology}

The methodology for the identification of risk used in this work was the method Checklists that produce a detailed diagnosis, identifying potential hazards in the process plant by applying to experience daily operations and effects of prior via a checklist. Therefore, the main task is to identify and evaluate the hazards of the process.

Once you identify risk, assess risk in relation to the magnitude (Table 1) and the probability of occurrence (Table 2).

The intersection of probability, in relation to the magnitude of the result of an event results in the categorization of risks defining five categories. One of the tasks in relation to risk management is to decide on the acceptability or otherwise of risk, thereby creating the basis for decision making.

Thus, we obtain the following indicators for decision making:

- Risk Category 1 (negligible risk) and 2 (lower risk) do not have the need for intervention.

- Risk Category 3 (moderate risk) need an intervention.

- Risk category 4 (unacceptable risk) require urgent intervention.

- Risk Category 5 (absolutely unacceptable risk) need a thorough and urgent intervention.

The colors of Figure 1 are merely illustrative, not match the colors of the risk groups used in Table 4 .

Table 1. Parameters for assessing the magnitude of an event.

\begin{tabular}{|c|c|c|}
\hline Characteristics & Magnitude & Classe \\
\hline $\begin{array}{l}\text { - } \quad \text { Causes no injuries and no damage to health in employees and others. } \\
\text { - } \quad \text { Causes no environmental impact } \\
\text { - } \quad \text { It does not cause stop in production } \\
\text { - } \quad \text { Causes mild and reversible injury to the health of employees and others }\end{array}$ & Negligible & I \\
\hline $\begin{array}{l}\text { - } \quad \text { Causes mild and reversible impacts to the environment within the property } \\
\text { - } \quad \text { Causes stop in short production } \\
\text { - } \quad \text { Causes little change in product quality }\end{array}$ & Marginal & II \\
\hline $\begin{array}{l}\text { - Causes severe injuries to the environment inside the property, sometimes irreversible and } \\
\text { mild injury outside the property. } \\
\text { - Causes serious damages to equipment, materials and installations of the property. } \\
\text { - May cause long term interruption of the production } \\
\text { Causes heavy changes o the product quality }\end{array}$ & Critical & III \\
\hline $\begin{array}{l}\text { - Can cause death, serious injury to the health of employees and contractors, and members of society } \\
\text { - } \quad \text { Causes damage of major consequence to the internal or external environment of the property } \\
\text { - } \quad \text { May cause permanent interruption of the production } \\
\text { - } \quad \text { May cause severe changes on the product quality }\end{array}$ & Catastrophic & IV \\
\hline
\end{tabular}

Source: FELICIANO, 2006 [8]. 


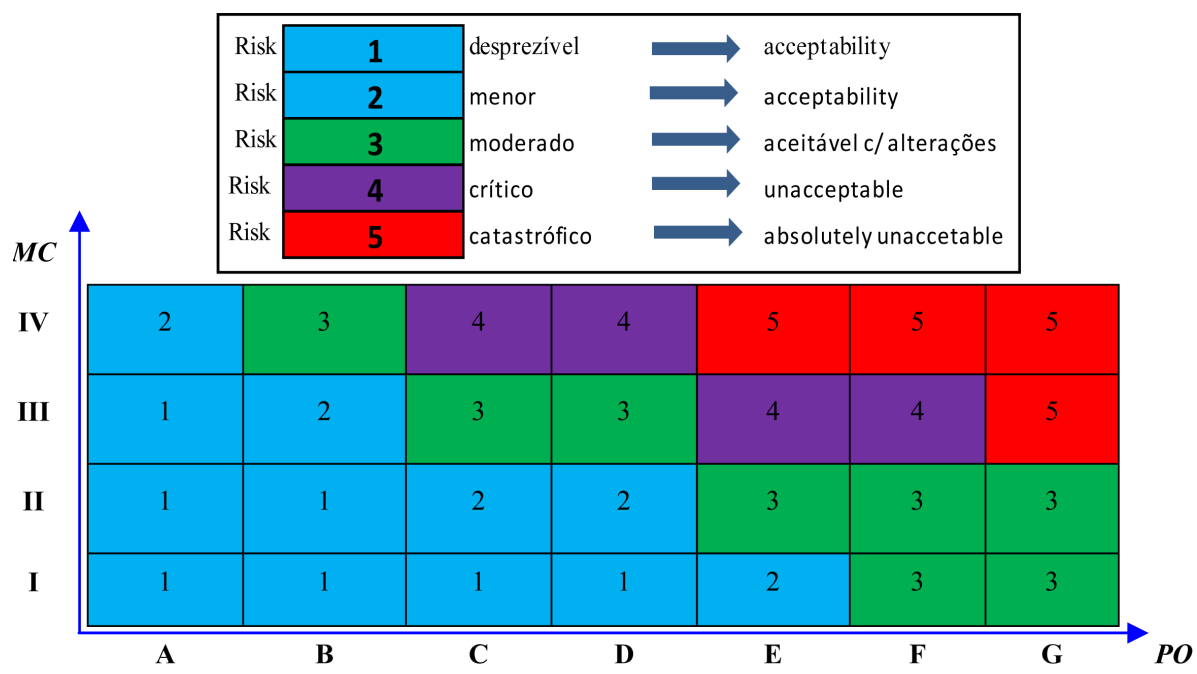

Figure 1. Intersection of $\mathrm{PO}$ with the $\mathrm{MC}$ of the event defining and quantifying risk acceptability. Source: FELICIANO, 2006 [8].

Table 2. Parameters for assessing the probability of an event.

\begin{tabular}{|c|c|c|c|}
\hline Characteristics & PO/YEAR & Probability & Classe \\
\hline Theoretically possible but unlikely to occure throughout the life of the installation & $<10^{-4}$ & Extremely remote & A \\
\hline Occurrence not expected over the lifetime of the facility & $10^{-3}$ a $10^{-4}$ & Remote & B \\
\hline Low probability over the life of the installation & $10^{-2}$ a $10^{-3}$ & Unlikely & $\mathrm{C}$ \\
\hline Expected occurrence once or twice throughout the life of the installation & $10^{-1}$ a $10^{-2}$ & Likely & $\mathrm{D}$ \\
\hline Expected occurrence once or twice every 10 years & $10^{0}$ a $10^{-1}$ & Frequent & $\mathrm{E}$ \\
\hline Expected occurrence once or twice in each 1 year & $>10^{0}$ & Very frequent & $\mathrm{F}$ \\
\hline Expected occurrence once or twice each month & $>10^{1}$ & Routine & G \\
\hline
\end{tabular}

Source: FELICIANO, 2006 [8].

\section{Preparation of an Environmental Risk Map}

\subsection{Main Sources of Risk in the Workplace}

In Table 3, we list the unit laboratory environments in which we studied the risks, according to the activities.

In physical chemical analysis laboratory quality tests to control quality of pesticide formulations are conducted. In classical analytical and chromatographic laboratories tests are performed to determine the amount of active ingredient contained in pesticides formulations.

Table 4 shows the results of the risk assessment relating to the installations, a unit of Chemistry Laboratory divided in different risk groups chosen (except biological risk), according to the activities performed in the laboratory.

\subsection{Map of Environmental Risk of a Chemical Laboratory Unit}

In order to enable performance proactively for reducing impacts to the work environment, of the environmental laboratory unit, the risk map (Figure 2) was prepared based on contributions from employees of the unit, indicating the risks that are felt and observed, according to its sensitivity and its activities.

\subsection{Decision-Making}

Risk management is in the process of decision making after the diagnosis of risk assessment. Therefore according 
Table 3. Assignment of the facilities of the laboratory.

\begin{tabular}{cc}
\hline SIGNE & DESCRIPTION \\
\hline L 1 & Physical chemical analysis laboratory \\
L 2 & Classical analysis \\
L 3 & Chromatography \\
S 1 & Reception and Screening \\
S 2 & File \\
S 3 & Technician Room \\
S 4 & Meeting Room \\
S 5 & Scale Room \\
S 6 & Water Purification \\
S 7 & Quality Unit Assurance \\
& Kitchen \\
& Sample Distribution \\
& Glassware Cleaning \\
& \\
& \\
& Shower \\
& \\
&
\end{tabular}

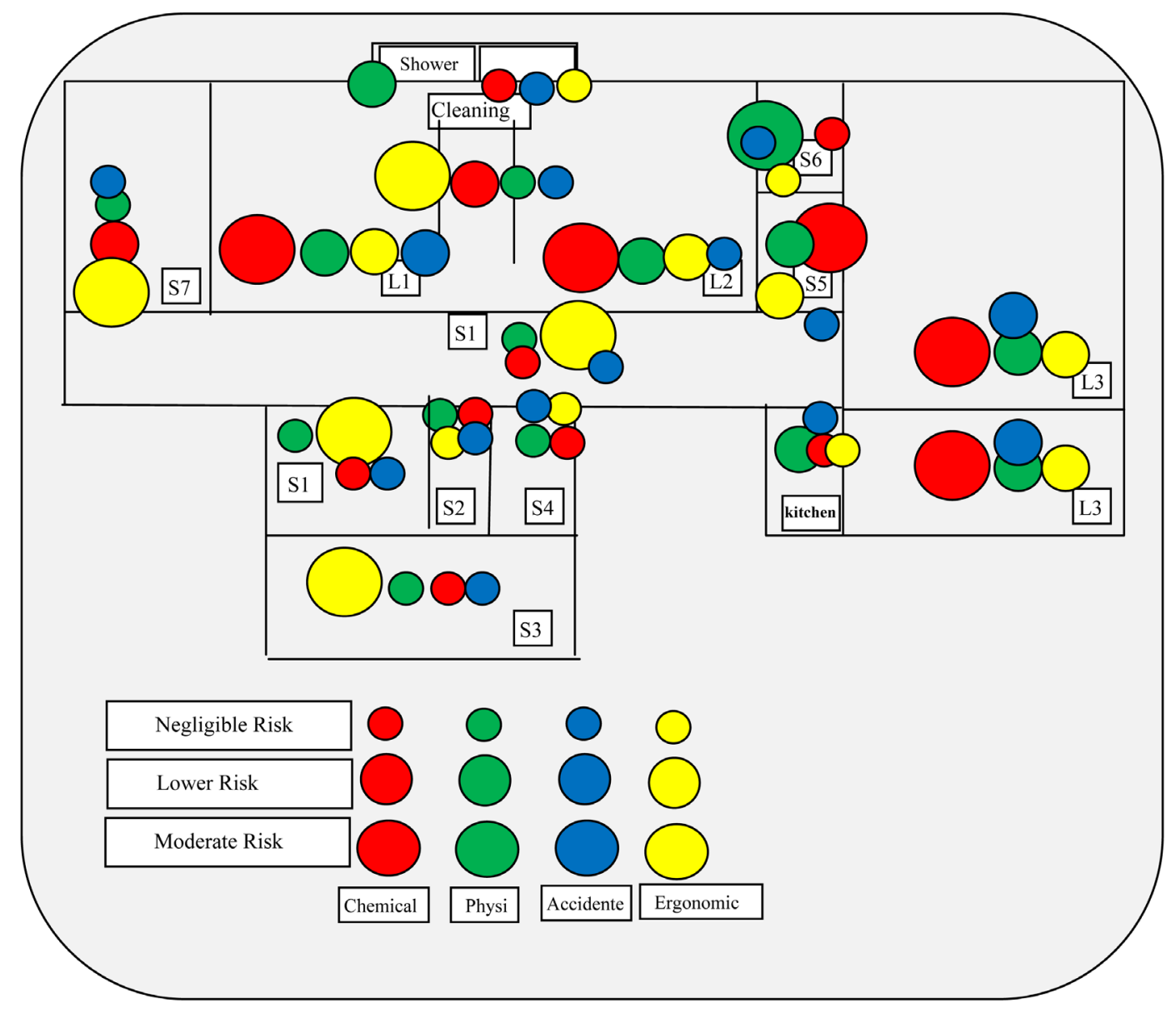

Figure 2. Risk map. 
Table 4. Evaluation of occupational risk in existing facilities and equipment in the chemistry laboratory.

\begin{tabular}{|c|c|c|c|c|c|c|c|c|c|c|c|c|c|c|c|c|c|c|c|c|c|c|}
\hline \multirow[b]{3}{*}{ Facilities } & \multicolumn{6}{|c|}{ Green Physical Risk } & \multicolumn{6}{|c|}{ Red Chemical Risk } & \multicolumn{4}{|c|}{$\begin{array}{c}\text { Yellow } \\
\text { Ergonomic Risk }\end{array}$} & \multicolumn{6}{|c|}{ Blue Accidental Risk } \\
\hline & \multicolumn{2}{|c|}{ Heat/cold } & \multicolumn{2}{|c|}{ Radiation } & \multicolumn{2}{|c|}{ Pressure } & \multicolumn{2}{|c|}{$\begin{array}{l}\text { Chemical } \\
\text { products }\end{array}$} & \multicolumn{2}{|c|}{ Gases } & \multicolumn{2}{|c|}{ Vapores } & \multicolumn{2}{|c|}{ Ergonomic } & \multicolumn{2}{|c|}{$\begin{array}{l}\text { Working } \\
\text { condition }\end{array}$} & \multicolumn{2}{|c|}{ Electricity } & \multicolumn{2}{|c|}{$\begin{array}{c}\text { Fire } \\
\text { explosion }\end{array}$} & \multicolumn{2}{|c|}{$\begin{array}{c}\text { Administration } \\
\text { failure }\end{array}$} \\
\hline & MC & PO & MC & PO & MC & PO & MC & PO & MC & PO & MC & PO & MC & PO & MC & PO & MC & PO & MC & PO & MC & PC \\
\hline $\begin{array}{l}\text { Physical chemical } \\
\text { analysis laboratory }\end{array}$ & II & $\mathbf{D}$ & II & B & III & B & III & D & II & B & III & C & II & C & III & B & II & B & II & D & II & B \\
\hline Classical analysis & II & D & II & B & III & B & III & D & II & B & III & C & III & B & III & B & II & B & II & B & II & B \\
\hline Chromatography & II & D & II & B & III & B & III & D & II & B & III & C & III & B & III & B & II & B & III & B & II & B \\
\hline $\begin{array}{l}\text { Reception and } \\
\text { Screening }\end{array}$ & II & B & II & B & II & B & II & B & II & C & II & C & III & B & III & B & II & B & II & $\mathbf{A}$ & II & B \\
\hline File & $\mathbf{I}$ & A & $\mathbf{I}$ & A & $\mathbf{I}$ & A & II & B & II & C & II & C & III & B & III & B & II & B & $\mathbf{I}$ & $\mathbf{A}$ & II & B \\
\hline Technician Room & $\mathbf{I}$ & A & $\mathbf{I}$ & A & $\mathbf{I}$ & A & II & B & II & C & II & C & III & B & III & C & II & B & I & A & I & A \\
\hline Meeting Room & I & A & I & A & I & A & II & B & II & C & II & C & III & B & III & C & II & B & I & A & I & A \\
\hline Scale Room & II & $\mathbf{D}$ & II & $\mathbf{B}$ & III & B & III & D & II & B & III & C & III & B & III & B & II & B & $\mathbf{I}$ & A & II & B \\
\hline Water Purification & III & D & $\mathbf{I}$ & A & $\mathbf{I}$ & A & II & B & II & C & II & C & II & B & II & B & II & B & $\mathbf{I}$ & $\mathbf{A}$ & II & B \\
\hline $\begin{array}{l}\text { Quality Unit } \\
\text { Assurance }\end{array}$ & II & B & II & B & II & B & II & B & II & C & II & C & II & B & III & C & II & B & $\mathbf{I}$ & $\mathbf{A}$ & $\mathbf{I}$ & A \\
\hline Kitchen & II & $\mathbf{D}$ & II & B & III & B & II & B & II & C & II & C & II & B & II & B & II & B & $\mathbf{I}$ & A & $\mathbf{I}$ & A \\
\hline $\begin{array}{c}\text { Sample } \\
\text { Distribution }\end{array}$ & II & B & II & B & II & B & II & C & $\mathbf{I}$ & $\mathbf{A}$ & $\mathbf{I}$ & A & II & B & II & B & II & B & $\mathbf{I}$ & $\mathbf{A}$ & $\mathbf{I}$ & A \\
\hline Glassware Cleaning & II & B & II & B & II & B & II & C & $\mathbf{I}$ & $\mathbf{A}$ & $\mathbf{I}$ & A & II & C & III & C & II & B & $\mathbf{I}$ & A & II & B \\
\hline Shower & II & C & II & B & II & B & II & B & II & B & II & B & II & B & II & B & II & B & I & A & I & A \\
\hline
\end{tabular}

to the mapping prepared, risks identified as moderate are acceptable, but require changes. We verified that exist moderate chemical risks in the laboratories indicated L1, L2, L3 and the room S 5; moderate physical risk in room for water purification and finally moderate ergonomic risk in rooms S1, S3, S7 and washing area for glassware.

Regarding moderate chemical risk, we must optimize the use of PPE in order to demonstrate the importance of identified hazards to all workers involved in the process. For moderate risk physical and ergonomic training should be intensified, enabling operational awareness. Other facilities had acceptable risks.

\section{Discussion and Conclusion}

The classification of environmental risk built for Chemistry Laboratory is part of the set of standard operating procedure of quality management.

The analysis of the risk assessment is a key tool to support risk management activities considered dangerous and assist in decision making.

Although the Laboratory Unit is an unhealthy environment, all preventive actions implemented based on normative and regulatory rules helped to minimize the risk of environmental and occupational injury. This explains the low risk rating in the graphic representation of the risk map in the Laboratory of Environmental Chemistry. However, this process is dynamic, and so continuity in the quality of the work environment, training, compliance with the standards must always be a priority in risk management.

\section{References}

[1] Bernstein, P. (1997) Desafio aos Deuses: A Fascinante História do Risco. Gulf Professional Publishing, Houston.

[2] Miller, G.T. (2008) Ciência Ambiental. Cengage Learning, São Paulo.

[3] Associação Brasileira DE Normas Técnica (2007) NBR 13075: Agrotóxicos e Afins: Segurança na Manipulação de Produtos Agrotóxicos e Afins, Rio de Janeiro. 
[4] Associação Brasileira de Normas Técnica (2003) NBR 13073: Agrotóxicos e Afins: Limpeza de Vidraria para uso em Ensaios de Produtos Agrotóxicos e Afin, Rio de Janeiro.

[5] Brasil. Ministério de Trabalho, Portaria no 3.214, 08 de junho de 1978. DOU, Poder Executivo, Brasília, DF, 06/07/78Suplemento

[6] Companhia Ambiental do Estado de São Paulo (CETESB). Norma Técnica P4.261: Orientação para a Elaboração de Estudos de Análise de Riscos. São Paulo, Maio, 2003.

http://www.cetesb.sp.gov.br/servicos/normas---cetesb/43-normas-tecnicas---cetesb

[7] Pmbok Project Management Institute (2004) Um guia do Conjunto de Conhecimentos em Gerenciamento de Projetos: guia PMBOK. 3rd Edition, PMI, Pennsylvania.

[8] Feliciano, W.F. (2006) Análise de Risco Ambiental. CRQ IV, 2006.

http://www.crq4.org.br/downloads/AnaliseRiscos_wanderley.pdf 